\title{
Hypoxic induction of vasculogenic mimicry in hepatocellular carcinoma: role of HIF-1 a, RhoA/ROCK and Rac1/PAK signaling
}

\author{
Ji-Gang Zhang ${ }^{\dagger}$, He-Ming Zhou ${ }^{\dagger}$, Xue Zhang, Wan Mu, Juan-Ni Hu, Gao-Lin Liu* and Qin Li
}

\begin{abstract}
Background: Vasculogenic mimicry (VM), defined as a capability of aggressive tumor Cells to mimic embryonic vasculogenic networks, caused poor prognosis in hepatocellular carcinoma (HCC). Rho kinases (ROCK), p21-activated kinase (PAK), hypoxia or epithelial-mesenchymal transition (EMT) contributed to the VM potential. However, the details underlying these biological behaviors have not been completely elucidated.

Methods: Kaplan-Meier analysis was conducted to predict relationship with hypoxia Inducible factor (HIF-1a), EMT related markers: Vimentin and patient prognosis. CD34/periodic acid-Schiff (PAS) double staining was examined to differentiate VM-positive (VM+) and VM-negative (VM-) samples. Cells were cultured under controlled hypoxic environments (1\% O2) or normoxic conditions. The effect of hypoxia on RhoA/ROCK, Rac1/PAK and EMT were evaluated by real time-qPCR and western blot. HIF-1a small interfering RNA (siRNA), overexpressed or short hairpin RNA (shRNA) of ROCK and kinase inhibitors were used to explore the effect of HIF-1a, RhoA/ROCK, Rac1/PAK and Vimentin on VM.
\end{abstract}

Results: HIF-1a or Vimentin was upregulated in VM+ HCC tissues, compared to non-cancerous tissues $(P<0.01)$, and patients with high expression of HIF-1a or Vimentin had worse prognosis $(P<0.001)$. We showed hypoxia induced RhoA/ROCK and Rac1/PAK signaling transduction, and EMT could be repressed by HIF-1a siRNA. Notably, RhoA/ROCK or Rac1/PAK stabilized HIF-1a in hypoxia, whereas HIF-1a did not significantly altered RhoA/ROCK or Rac1/PAK signaling in hypoxia. Moreover, we found distinct roles of ROCK1, ROCK2 and PAK in regulating Vimentin phosphorylation.

Conclusions: RhoA/ROCK and Rac/PAK signaling played crucial roles in hypoxia-induced VM via Ser72 and Ser56 Vimentin phosphorylation in HCC.

Keywords: HIF-1a, RhoA/ROCK, Rac1/PAK, Vimentin;Vasculogenic mimicry

\section{Background}

Hepatocellular carcinoma (HCC) is a prevalent malignancy, of which incidence and mortality rates have remained at a higher level [1]. While there have been some advanced strategy of diagnosis and treatment applied to clinical practice [2], the dismal outcome and poor median survival of patients have been largely unchanged for decades. Tumors required an endothelialindependent blood supply to break through the limitations

\footnotetext{
* Correspondence: gaolinliu@aliyun.com; liqin0626@hotmail.com

${ }^{\dagger} \mathrm{Ji}$-Gang Zhang and He-Ming Zhou contributed equally to this work.

Department of Clinical Pharmacy, Shanghai General Hospital, Shanghai Jiao

Tong University School of medicine, No.100 Haining Road, Shanghai 200080,

People's Republic of China
}

(c) The Author(s). 2020 Open Access This article is distributed under the terms of the Creative Commons Attribution 4.0 International License (http://creativecommons.org/licenses/by/4.0/) which permits unrestricted use, distribution, and reproduction in any medium, provided you give appropriate credit to the original author(s) and the source, provide a link to the Creative Commons license, and indicate if changes were made. The Creative Commons Public Domain Dedication waiver (http://creativecommons.org/publicdomain/zero/1.0/) applies to the data made available in this article, unless otherwise stated. (VM), which was first described by Maniotis et al. [3]. Our previous reports have discovered that VM and mosaic vessels are involved in HCC and played a critical role in promoting cancer metastasis, invasion, which led to poor prognosis $[4,5]$. Therefore, it is indispensable to investigate more about pathological mechanism involved.

Hypoxia is one of the most ordinary phenomenon in tumor microenvironment on account of the abundant oxygen and energy consumption [6]. Several studies have shown the stimulative effect on hypoxia-inducible factor- $1 \alpha$ (HIF-1 $\alpha)$ activity, which played a critical role in regulating the adaption of carcinomas to hypoxia [7], 
on $\mathrm{VM}$ formation $[5,8,9]$. The p21-activated kinases (PAKs) belong to a family of serine/threonine kinases that act as effectors of the Rho-related GTPases like Rac and Cdc42 [10]. PAK phosphorylate a series of proteins controlling cytoskeletal remodeling, cell survival and motility as well. Given the bulk of hypoxic regions in solid tumors, elucidating links between PAK and HIF- $1 \alpha$ in hypoxic cancer cells may further unveil details in mechanisms of cancer development. Rho kinase (ROCK) [11], was associated with cell migration, invasion, cellcell adhesion [12-14]. Our previous report mentioned that ROCK plays an important mediated role in the process of cancer cell VM formation [4]. Recently, a great deal of researches have applied RNAi technology to independently disrupt each paralog of ROCK (ROCK1 and ROCK2) in vitro and have unveiled unique roles for either ROCK1 or ROCK2 in the control of actincytoskeleton dynamics and cell morphogenesis, migration, cell fate decisions, and extracellular matrix assembly $[15,16]$. Therefore, HIF- $1 \alpha$, ROCK isoforms and PAK seemed to be potential molecular targets for the investigation of $\mathrm{VM}$ research.

During epithelial-mesenchymal transition (EMT), epithelial cells gradually dedifferentiate, lose cell polarity with epithelial surface markers degeneration, turning to expressing mesenchymal markers, displaying phenotypic alterations, similar to $\mathrm{VM}$ process, which mimicked endothelial cells possessing the capability of tube formation. Recently, EMT has been considered as a mechanism leading to $\mathrm{VM}[17,18]$. The molecular transitions for EMT are the upregulation of mesenchymal components, like Vimentin and $\mathrm{N}$-cadherin and the decrease of E-cadherin expression, which belongs to epithelial cell adhesion molecules [19].

RhoA and Rac pathways are the two principle signaling pathways which implicated in both mechanosensing and the regulation of the Vimentin network. ROCK or PAK was involved in Vimentin phosphorylation and rearrangement $[20,21]$. Nevertheless, the mystery of molecular mechanism between HIF- $1 \alpha$, RhoA/ROCK, Rac1/PAK and Vimentin have not been fully unveiled.

Here, we are trying to investigate RhoA/ROCK and Rac1/PAK expression triggered by hypoxia in order to explore whether HIF- $1 \alpha$ activation is significant for VM formation as well as inducing the EMT phenotype. As far as we know, this research is the first study elaborating the relationship between HIF-1 $\alpha$, RhoA/ROCK, Rac1/PAK and EMT in HCC exposed to hypoxia.

\section{Methods}

\section{Collection of patient samples}

In total, 80 pairs of HCC tissues and adjacent nontumorous liver tissues were purchased from ShGnghGi Outdo Biotech Company (China). Three patients were ruled out for lacking completed clinical and follow-up data. Written informed consent was obtained from all subjects, and the study was approved and supervised by the Ethics Committee of the Shanghai General Hospital, Shanghai Jiao Tong University School of Medicine. The completely pathological and clinical features of all the patients were shown and stored in Table 1.

\section{Materials; antibodies and cell lines}

Materials, chemical agents and antibodies applied in this research included Matrigel (BD Biosciences); C3 transferase and Y27632 (Sigma-Aldrich); NSC23766 and IPA (Selleck); cell culture media (DMEM); fetal bovine serum (FBS) and antibiotics (Gibco); Furthermore, the information of antibodies was listed in Additional file 1: Table S1.

MHCC97H cell lines were obtained from the Liver Cancer Institute, Zhongshan Hospital, Fudan University (Shanghai, China). Cell lines were cultured in DMEM supplemented with $10 \% \mathrm{FBS}$ and $1 \%$ antibiotics, maintained at $37{ }^{\circ} \mathrm{C}$ in a humidified atmosphere of $5 \% \mathrm{CO}_{2}$,

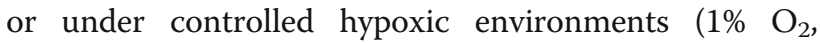
$5 \% \mathrm{CO}_{2}$ and $94 \% \mathrm{~N}_{2}$.)

\section{RNA interference (RNAi)}

MHCC97H cells were transfected with a validated small interfering RNA (siRNA) targeting the HIF-1 $\alpha$ sequence, 5'-GCAAUAGACAAGGACAUAATT-3' (synthesized by Shanghai GenePharmaCo., Ltd. China). Lipofectamine $^{\mathrm{Tm}} 2000$ reagent (Invitrogen, USA) was utilized to perform the transfection according to the manufacturer's protocol, and the cells were incubated at $37^{\circ} \mathrm{C}$ for $48 \mathrm{~h}$ before analysis. $48 \mathrm{~h}$ later, western blot assay was conducted to confirm the gene silencing effects.

\section{Establishing ROCK1 \& ROCK2 overexpressing cells}

One day before transfection, $2 \times 10^{4}$ HCC were seeded into 24-well plate. Lenti-virus (Obio, Shanghai, China) was applied to transduce the cells with the corresponding vectors. $24 \mathrm{~h}$ later, the transduced cells were diluted with proportion of 1:100 and plated into a 100-mm culture dish. In order to select for cells overexpressing ROCK1\&2, the cells were cultured in medium with $5 \mu \mathrm{g} / \mathrm{mL}$ puromycin for 14 days. Clones displaying puromycin resistance and expressing the fluorescent label (Flag) survived and expanded.

As for lentivirus construction, short hairpin RNA (shRNA) for ROCK1 or ROCK2 and the negative control were cloned into the lenti knockdown vector pLenti-U6shRNA-CMV- EGFP-T2A-Puro to produce Lenti-U6shRNA (ROCK1 or ROCK2)-CMV- EGFP-T2A-Puro. The core target sequences of the shRNA are presented in Additional file 2: Table S2. Moreover, the full length of ROCK1 or ROCK2 was cloned into the overexpress vector Lenti-CMV-MCS-3FLAG-PGK-Puro H156 to produce pLenti-CMV-(ROCK1 or ROCK2)-3FLAG-PGK-Puro 
Table 1 Associations between HIF-1a, Vimentin and clinico-pathological characteristics in HCC

\begin{tabular}{|c|c|c|c|c|c|c|c|}
\hline \multirow[t]{2}{*}{ Variant } & \multirow{2}{*}{$\begin{array}{l}\text { No. of } \\
\text { patients }\end{array}$} & \multicolumn{2}{|l|}{ HIF-1a } & \multirow[t]{2}{*}{$p$-value } & \multicolumn{2}{|l|}{ Vimentin } & \multirow[t]{2}{*}{$p$-value } \\
\hline & & Low(\%) & High(\%) & & Low(\%) & High(\%) & \\
\hline Cases & 77 & $34(44.2)$ & $43(55.8)$ & & $27(35.1)$ & $50(64.9)$ & \\
\hline \multicolumn{8}{|l|}{ Age (years) } \\
\hline$\leq 60$ & 62 & $28(45.2)$ & $34(54.8)$ & $0.718^{\mathrm{a}}$ & 21(33.9) & $41(66.1)$ & $0.655^{a}$ \\
\hline$>60$ & 15 & $6(40.0)$ & $9(60.0)$ & & $6(40.0)$ & $9(60.0)$ & \\
\hline \multicolumn{8}{|l|}{ Gender } \\
\hline Male & 63 & $27(42.9)$ & $36(57.1)$ & $0.626^{a}$ & 19(30.2) & $44(69.8)$ & $0.056^{\mathrm{a}}$ \\
\hline Female & 14 & $7(50.0)$ & $7(50.0)$ & & $8(57.1)$ & $6(42.9)$ & \\
\hline \multicolumn{8}{|l|}{ Tumor size $(\mathrm{cm})$} \\
\hline$\leq 3$ & 35 & $18(51.4)$ & $17(48.6)$ & $0.241^{\mathrm{a}}$ & $15(42.9)$ & $20(57.1)$ & $0.191^{\mathrm{a}}$ \\
\hline$>3$ & 42 & $16(38.1)$ & $26(61.9)$ & & $12(28.6)$ & $30(71.4)$ & \\
\hline \multicolumn{8}{|l|}{ Clinical stage } \\
\hline$|/| \mid$ & 42 & $23(54.8)$ & $19(45.2)$ & $0.065^{\mathrm{a}}$ & $20(47.6)$ & $22(52.4)$ & $0.011^{\mathrm{a} *}$ \\
\hline III/IV & 35 & 11(31.4) & $24(68.6)$ & & $7(20.0)$ & $28(80.0)$ & \\
\hline \multicolumn{8}{|l|}{ Invasion depth } \\
\hline $\mathrm{T} 1+\mathrm{T} 2$ & 40 & $16(40.0)$ & $24(60.0)$ & $0.445^{\mathrm{a}}$ & $17(42.5)$ & $23(57.5)$ & $0.155^{\mathrm{a}}$ \\
\hline $\mathrm{T} 3+\mathrm{T} 4$ & 37 & 18(48.6) & 19(51.4) & & $10(27.0)$ & $27(73.0)$ & \\
\hline \multicolumn{8}{|c|}{ Lymph nodes metastasis } \\
\hline No (negative) & 46 & $25(54.3)$ & $21(45.7)$ & $0.028^{\mathrm{a} *}$ & $22(47.8)$ & $24(52.2)$ & $0.016^{\mathrm{a} *}$ \\
\hline N1 (positive) & 31 & $9(29.0)$ & $22(71.0)$ & & $7(21.2)$ & $24(78.8)$ & \\
\hline \multicolumn{8}{|l|}{ Distant metastasis } \\
\hline MO (absent) & 72 & $33(45.8)$ & $39(54.2)$ & $0.510^{b}$ & $25(34.7)$ & $47(65.3)$ & $0.811^{b}$ \\
\hline M1 (present) & 5 & $1(20.0)$ & $4(80.0)$ & & $2(40.0)$ & $3(60.0)$ & \\
\hline \multicolumn{8}{|l|}{ VM } \\
\hline Negative & 50 & $27(54.0)$ & $23(46.0)$ & $0.018^{a *}$ & $22(44.0)$ & $28(56.0)$ & $0.025^{\mathrm{a} *}$ \\
\hline Positive & 27 & $7(25.9)$ & $20(74.1)$ & & $5(18.5)$ & $22(81.5)$ & \\
\hline
\end{tabular}

${ }^{a}$ Chi-square test

${ }^{b}$ Fisher's exact test

${ }^{*} P<0.05$ indicates a significant association among the variables

(Obio Technology Co., Ltd., Shanghai, China), the primers for amplification of ROCK1 and 2 are listed in Additional file 2: Table S2. The stable knockdown and overexpression of ROCK1 or ROCK2 was confirmed by Western blotting.

\section{Immunohistochemical (IHC), CD34/PAS double staining and scoring}

The tissue slices were deparaffinized, hydrated according to standard protocols. Antigen retrieval was performed, and unspecific binding sites were blocked using BSA. Then, the slices were incubated within a series of primary antibodies (Additional file 1: Table S1) overnight at $4{ }^{\circ} \mathrm{C}$, and the corresponding secondary antibody was incubated with each slice at $37^{\circ} \mathrm{C}$ for $30 \mathrm{~min}$. The color was developed by a 3,3'-diaminobenzidine chromogen (DAB, Gene Tech GTVisionIII Detection Kit, Shanghai, China) solution. All of the slices were counterstained with hematoxylin, dehydrated, and mounted.
Immunohistochemical staining with CD34 was performed on the sections as described above prior to PAS staining. Then, the slides were treated with periodic acid solution for $10 \mathrm{~min}$ and rinsed with distilled water for 5 min. In a dark chamber, the slides were submerged in Schiff solution for $15 \mathrm{~min}$ at $37^{\circ} \mathrm{C}$. After washing the slides under running water for $20 \mathrm{~min}$, all of the sections were counterstained with hematoxylin, dehydrated, and mounted. VM channels surrounded by HCC cells were positive for PAS staining, but negative for CD34.

At least 10 visual fields for each slides were observed per slide using a double-blind method by two independent investigators according to the staining area and intensity. The percentage of the staining area was scored as follows: 0 (negative staining), 1 (1-25\%), 2 (26-50\%), 3 (51-75\%), 4 (76-100\%). Staining intensity was graded as follows: 0 (no staining), 1 (weak staining), 2 (moderate staining), 3 (intense staining). The comprehensive score was calculated as 
staining percentage multiply intensity. The cases scoring $\geq 3$ were identified as positive expression.

\section{Western blot analysis}

Antibodies dilution in Additional file 1: Table S1. Western blot assay was repeated at least three times. The total proteins were extracted from various groups and electrophoresed by SDS-PAGE. The proteins in the gel were transferred onto a PVDF membrane (Merck-Millipore), and the membrane was blocked with 5\% non-fat milk dissolved in TBS containing 1\% Tween-20 (TBST) for $1 \mathrm{~h}$ at room temperature. The membrane was incubated with a primary antibody at $4{ }^{\circ} \mathrm{C}$ overnight, washed with $1 \%$ TBST three times, and incubated with an alkaline phosphatase-conjugated secondary antibody for $1 \mathrm{~h}$ at room temperature. After washing, the chemiluminescent signal was imaged using a ChemiDoc XRS (BioRad) and quantified using Image J. The experiment was repeated at least three times.

\section{Real-time qPCR analysis}

Total RNA was extracted from cells using Trizol (Invitrogen) and verified using electrophoresis. Then the cDNA was prepared by reverse-transcription kit (Thermo Fisher Scientific). Human GAPDH was used as endogenous control. The primer sequences used in $\mathrm{qPCR}$ was listed in Additional file 3: Table S3. The qPCR was performed on a 7900HT Sequence Detection System (ABI, Foster City, CA, USA). The relative expression of the mRNA was calculated by the $2-\Delta \Delta$ Ct method.

\section{Matrigel tube formation assay}

Tumor cell formation of the capillary structure was tested in vitro as previously described. Briefly, Matrigel was thawed at $4{ }^{\circ} \mathrm{C}$ overnight. Then, $100 \mu$ l Matrigel $(10 \mathrm{mg} / \mathrm{ml})$ was added into each well of a 24-well plate and allowed to solidify at $37^{\circ} \mathrm{C}$ for $1 \mathrm{~h}$. The cell suspension with or without treatment in culture medium $\left(2 \times 10^{4} / \mathrm{ml}\right)$ was seeded onto the Matrigelcoated 24-well plate, incubated in normoxia or hypoxia for indicated time, photographed, and counted using an inverted light microscope (Nikon, Japan).

\section{Analysis of RhoA activity}

The activity of RhoA was addressed using a biochemical assay that measures the amount of active, GTP-bound RhoA protein (G-LISA RhoA Activation Assay Biochem Kit (absorbance based); Cytoskeleton).

\section{Statistical analysis}

Data were expressed as the mean \pm S.E.M of three independent experiments with three biological replicates. Statistical analysis was performed by SPSS V.20.0 Software (SPSS Inc., Chicago, IL, USA). With student's t test,
Chi-squared test and Fisher's exact test, we analyzed the statistical significance. $P$ values $<0.05$ (two-tailed) were considered as statistically significant.

\section{Results}

\section{VM presented in HCC tissues}

CD34-PAS double staining was performed to detect VM. VM was defined as a pattern of blood supply in carcinoma without participation by endothelial cells. Endotheliumdependent vessels exhibited CD34+ on their luminal surface [22]. While, VM channels made of HCC cells were positive for PAS staining, but negative for CD34. As shown in Fig. 1a (yellow arrow indicating blood vessel; red arrow indicates VM channels), VM channels were presence in tumor tissues, but absence in corresponding non-cancerous tissues. Moreover, a Kaplan-Meier assay showed that patients who $\mathrm{VM}+$ tended to have a poor prognosis $\left({ }^{*} P<\right.$ 0.05; Fig. 1b).

\section{Correlated expression of HIF-1a and Vimentin in clinical HCC tissues}

To determine whether HIF- $1 \alpha$ was involved in VM development, we analyzed HIF- $1 \alpha$ and Vimentin expression in 77 pairs of $\mathrm{HCC}$ and adjacent non-cancerous specimens. The clinical data in Table 2 showed that HIF- $1 \alpha$ was highly expressed in 43 of 77 HCC tissues (55.8\%), Vimentin was expressed in 50 of 77 HCC tissues (64.9\%). Enhancive HIF- $1 \alpha$ and Vimentin expression was correlated with an increase in lymph nodes metastasis (" $P<0.05$; Table 1; Fig. 1c). Remarkably, our analysis data illustrated that the prevalence of VM was inextricably linked with the expression of HIF- $1 \alpha$ and Vimentin (Table 1). Moreover, a Kaplan-Meier assay showed that patients with high HIF- $1 \alpha$ expression or Vimentin expression tended to have a poor prognosis $\left({ }^{*} P<0.05\right.$; Fig. $1 d$, e). To verify this hypothesis: HIF- $1 \alpha$ and Vimentin were correlated in HCC patients, a correlation analysis data showed that HIF- $1 \alpha$ expression was positively correlated with Vimentin expression in HCC patients $(" P<0.05$, Table 3$)$. While there is no relationship detected between HIF- $1 \alpha$ or Vimentin protein and age, gender, tumor size, invasion depth and distant metastasis (Table 1). Moreover, comparing with other patients, VM positivity is significantly high in HIF- $1 \alpha$ and Vimentin double-high patients (**** $P<0.0001$, Table 4 ). Altogether, these data showed that both HIF-1 $\alpha$ and Vimentin were upregulated, and they could synergistically promote HCC progression and VM formation.

\section{Hypoxia regulated rho/ROCKs and Rac1/PAKs expression}

To query whether the RhoA/ROCK pathway is regulated by hypoxia, a time-dependent study of gene and protein expression assay was performed to compare levels of RhoA, ROCK1 or ROCK2 expression under hypoxia 


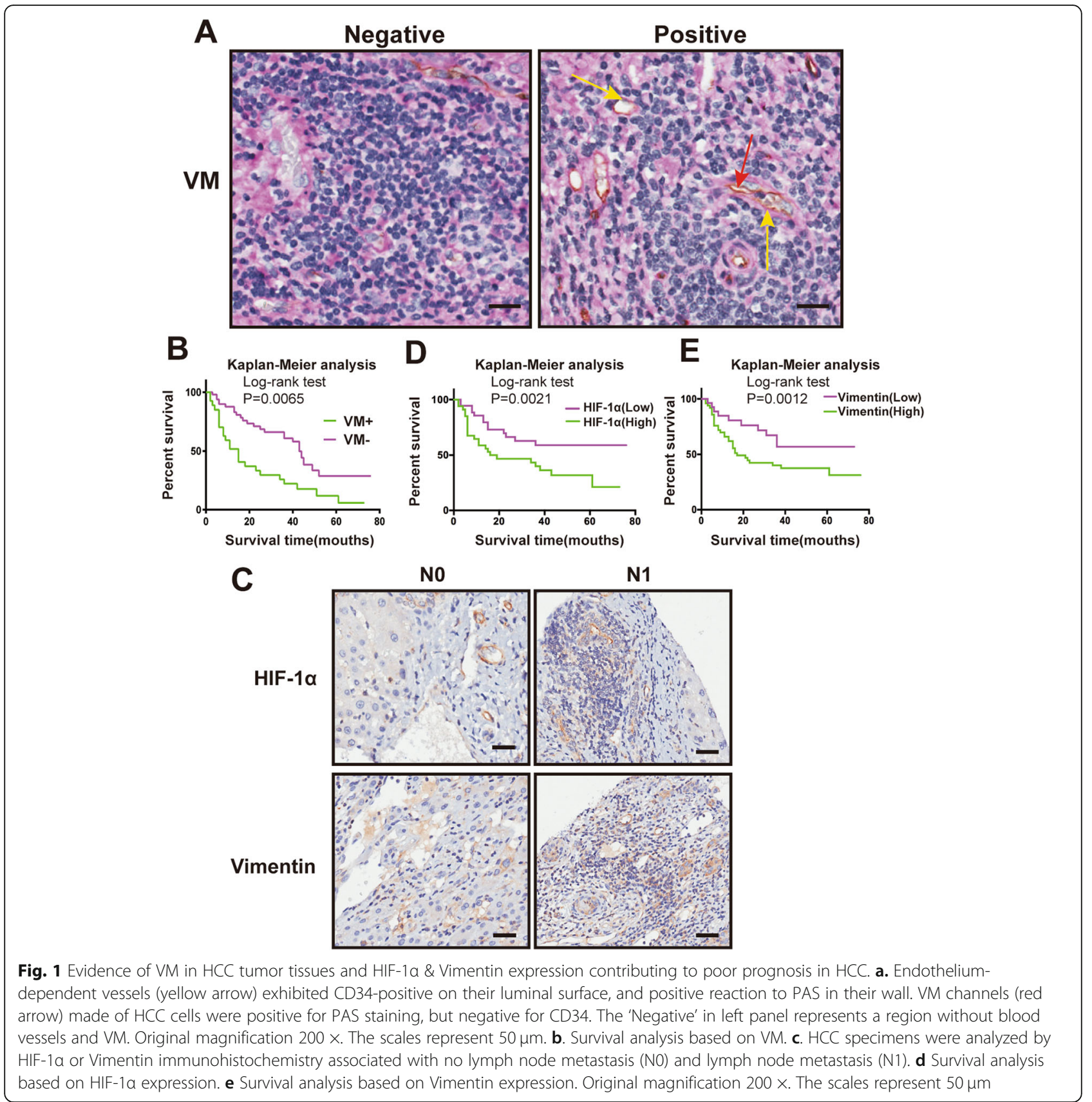

Table 2 Protein expression of HIF-1a and Vimentin in HCC cancer tissues and adjacent normal tissues

\begin{tabular}{|c|c|c|c|c|c|c|c|}
\hline \multirow[t]{2}{*}{ Tissue sample } & \multirow[t]{2}{*}{ No. of patients } & \multicolumn{2}{|l|}{ HIF-1a } & \multirow[t]{2}{*}{$P$-value } & \multicolumn{2}{|l|}{ Vimentin } & \multirow[t]{2}{*}{$P$-value } \\
\hline & & Low (\%) & High (\%) & & Low (\%) & High (\%) & \\
\hline Tumor & 77 & $34(44.2)$ & $43(55.8)$ & $0.000^{*}$ & $27(35.1)$ & $50(64.9)$ & $0.000^{*}$ \\
\hline Non-cancerous tissues & 77 & $66(85.7)$ & $11(14.3)$ & & $64(83.1)$ & 13(16.9) & \\
\hline
\end{tabular}

HIF-1a and Vimentin expression was measured in tumor and non-cancerous tissues. Both HIF-1a and Vimentin was higher in tumor tissues compared with noncancerous tissues. Data were analyzed using the Chi-squared test ${ }^{*} P<0.05$ indicates statistical significance 
Table 3 Correlation analysis between HIF-1a and Vimentin protein expression in HCC

\begin{tabular}{lllll}
\hline \multirow{2}{*}{$\begin{array}{l}\text { Tumor tissue } \\
\text { sample }\end{array}$} & HIF-1a & & $\begin{array}{l}\text { Correlation } \\
\text { coefficient }\end{array}$ & p-value \\
\cline { 2 - 3 } & Low & High & & \\
\hline Vimentin Low & 7 & 20 & -0.270 & $0.018^{*}$ \\
Vimentin High & 27 & 23 & & \\
\hline *P $<0.05$ indicates statistical significance & &
\end{tabular}

${ }^{*} P<0.05$ indicates statistical significance

conditions. Exposure of MHCC97H to hypoxia for 4-24 $\mathrm{h}$ did not produce any significant effect on RhoA mRNA (Fig. 2a, left panel), but increased its protein level between 4 and $8 \mathrm{~h}$ (Fig. 2b). To assess the activation state of RhoA, we used an ELISA-based assay that measures the level of GTP-bound RhoA. Exposure of MHCC97H to $1 \% \mathrm{O}_{2}(4 \mathrm{~h})$ induced a significant increase in RhoA activity (Fig. 2c). Similar to RhoA, exposure $\mathrm{MHCC} 97 \mathrm{H}$ to hypoxia did not affect the mRNA level of both ROCK1 and ROCK2 (Fig. 2a, middle and right panels). Interesting, hypoxia upregulated ROCK 2 protein level for $4 \mathrm{~h}$ and $8 \mathrm{~h}$, but did not affect the expression of ROCK1 (Fig. 2d, e). These results indicate that being exposed to $1 \% \mathrm{O}_{2}$ for $4 \mathrm{~h}$ showed the maximal synergistic effect. As a result, we used an incubation time of $4 \mathrm{~h}$ in the following experiments. Similar to RhoA/ROCKs, exposure of $\mathrm{MHCC} 97 \mathrm{H}$ to $1 \% \mathrm{O}_{2}(4 \mathrm{~h})$ induced a significant increase expression of Rac1 and PAK (Fig. 2f). Taken together, those data above provided evidence for hypoxia-dependent activity of RhoA/ROCK2 and Rac1/ PAK signaling in $\mathrm{HCC}$.

\section{RhoA/ROCKs and Rac1/PAK act upstream of HIF-1a}

HIF- $1 \alpha$ is the key regulatory component, because it is rapidly degraded in normoxic conditions but stabilized and activated in hypoxia [23, 24]. To test if HIF- $1 \alpha$ stabilization affects RhoA/ROCKs, Rac1/PAK, EMT and VM markers activity, knockdown HIF-1 $\alpha$ in $\mathrm{MHCC} 97 \mathrm{H}$ cells was established. In cells transfected with HIF- $1 \alpha$ siRNA, the HIF-1 $\alpha$ protein expression was intensely inhibited compared with that in control siRNA transfected cells (Fig. 3a). Inhibition of HIF-1 $\alpha$ did not affect RhoA/ROCKs and Rac1/PAK activity exposure of $\mathrm{MHCC} 97 \mathrm{H}$ to $1 \% \mathrm{O}_{2}(4 \mathrm{~h})$ (Fig. 3b, c). To examined whether RhoA/ROCKs and Rac1/PAK influenced HIF$1 \alpha$ in $\mathrm{HCC}$, the MHCC97H cells were treated with

Table 4 Correlation analysis between VM and HIF-1a, Vimentin protein expression in HCC

\begin{tabular}{lllll}
\hline $\begin{array}{l}\text { Tumor tissue } \\
\text { sample }\end{array}$ & VM & & $\begin{array}{l}\text { Correlation } \\
\text { coefficient }\end{array}$ & $p$-value \\
\cline { 2 - 4 } & Positive & Negative & & \\
\hline Double High & 18 & 5 & 0.5087 & $<0.0001^{* * *}$ \\
All others & 9 & 45 & & \\
\hline$* P<0.05$ indicates statistical significance & &
\end{tabular}

exoenzyme C3 (800 ng/ml, RhoA inhibitor), Y27632 (50 $\mathrm{MM}$, ROCK inhibitor), NSC23766 (50 $\mu \mathrm{M}$, Rac1 inhibitor) or IPA-3 $(10 \mu \mathrm{M}$, PAK inhibitor) in hypoxia. There were significant decline in HIF-1 $\alpha$ expression caused by all inhibitors (Fig. 3d, e), which was similar to other research [25]. These data indicate that RhoA/ ROCKs and Rac1/PAK proteins participate in the regulation of HIF- $1 \alpha$ in hypoxia, but that stabilization of HIF- $1 \alpha$ does not affect their activity, suggesting that RhoA/ROCKs and Rac1/PAK act upstream of HIF$1 \alpha$. As shown in Fig. 3b, HIF-1 $\alpha$ siRNA transfection resulted in significant Vimentin and VE-cadherin downregulation, E-cadherin upregulation $(* * P<0.01$ vs. Control siRNA, Fig. 3c), indicating HIF-1 $\alpha$ is involved in EMT and VM formation.

\section{HIF-1a-induced EMT and VM is rho/ROCK and Rac1/PAK dependent}

To detect whether Rho/ROCK had an inhibitory effect on HIF-1 $\alpha$-mediated neovascularization in hypoxia, we observed the morphology of cell seizure activity in culture medium containing exoenzyme C3, Y27632, NSC23766 or IPA-3, using Control siRNA as the positive control. Exposed to hypoxia (4h), HIF-1 $\alpha$ siRNA transfection resulted in significant Vimentin and VEcadherin downregulation, E-cadherin upregulation $\left({ }^{*} P<\right.$ 0.05 , ${ }^{* *} P<0.01$ vs. Control siRNA, Fig. $\left.4 \mathrm{a}, \mathrm{b}\right)$, indicating HIF- $1 \alpha$ induces EMT and VM. All inhibitors reversed the high expression induced by HIF- $1 \alpha\left({ }^{*} P<0.05,{ }^{* *} P<\right.$ 0.01 vs. Control siRNA, Fig. $4 \mathrm{a}, \mathrm{b})$. As shown in Fig. $4 \mathrm{c}$ and e, being exposed to hypoxia for $4 \mathrm{~h}$, HIF-1 $\alpha$ silencing in MHCC97H cells inhibited VM tubes in Matrigel, while control siRNA (HIF-1 $\alpha$ normal expression) facilitated VM development, which provided the first evidence addressing the importance of HIF-1 $\alpha$ in channel formation. Compared with control siRNA, exoenzyme C3, Y27632, NSC23766 or IPA-3 treatment triggered disappearance of these structures (Fig. 4d, f), suggesting that blockage of Rho/ROCK and Rac1/PAK vanished VM formation through reducing HIF-1 $\alpha$ activity. Altogether, those data indicated HIF- $1 \alpha$ is involved in EMT and VM formation in RhoA/ROCK and Rac1/PAK dependent manner exposed to hypoxia.

\section{PAK and ROCK2 facilitated VM by EMT via p-Vimentin}

\section{(Ser 72 and 56)}

To investigate the mechanism of PAK and ROCK 2 on VM formation, a quantitative protein analysis of Vimentin, Ser72-, Ser56- and Ser38-phosphorylated Vimentin were performed with western blotting. As shown in Fig. 5a, compared to the control, Ser56-phosphorylated Vimentin levels (not Ser-72 or Ser-38) significantly decreased in IPA-3 group, suggesting the potential role of Rac1/PAK on EMT subjected to hypoxia. 


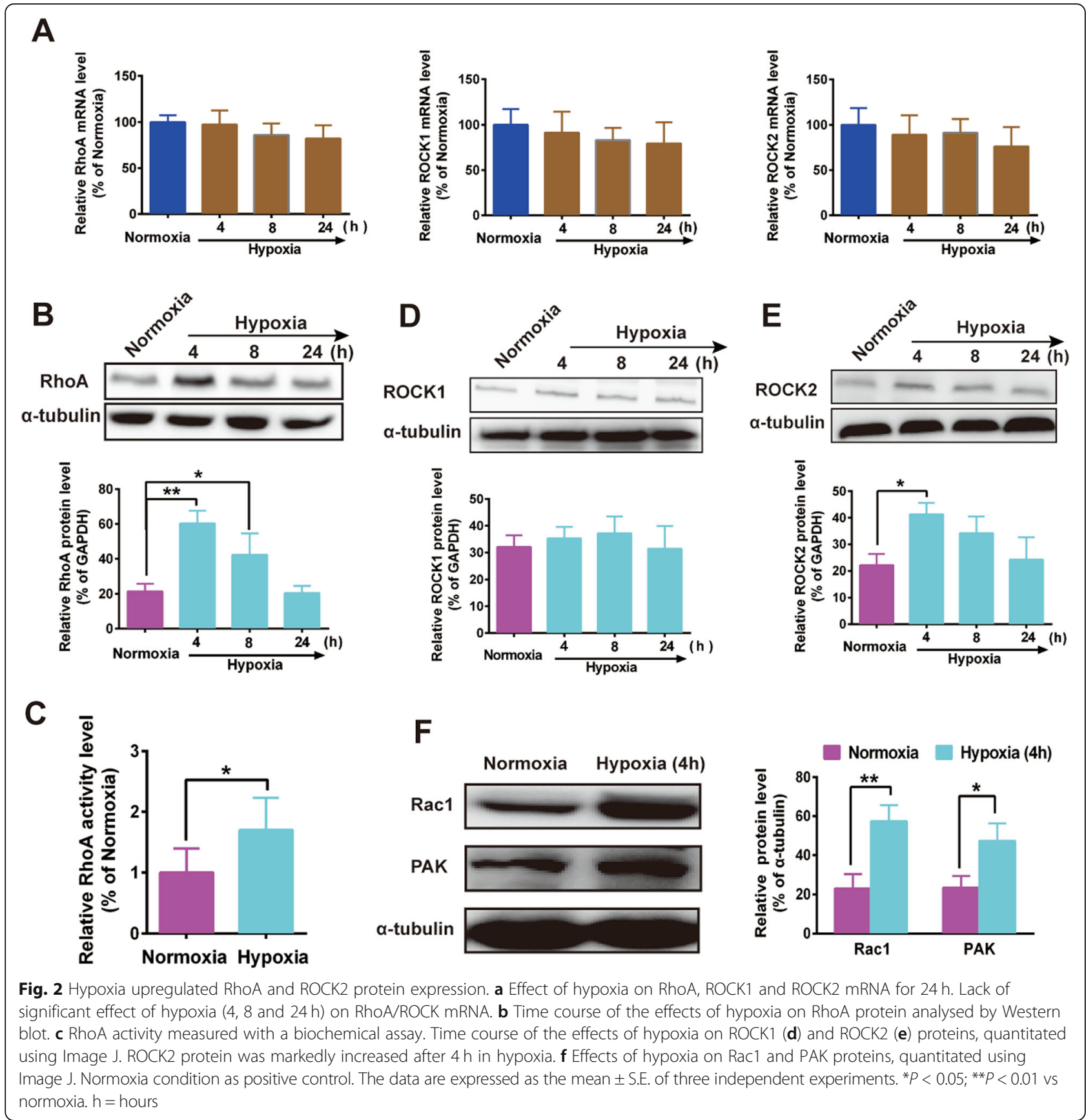

To further demonstrate the potential role of ROCK1 or ROCK2 on EMT in hypoxia, ROCK1 and ROCK2 stably expressing cells were established. As shown in Fig. $5 \mathrm{~b}$ and $\mathrm{d}$, both ROCK 1 and ROCK 2 were present at detectable levels, indicating that no cross-reactivity occurred between the two constructs.

ROCK is a key serine/threonine kinase responsible for the phosphorylation and subsequent rearrangement of Vimentin [26]. As shown in Fig. 5c, compared to Control shRNA, Ser72-phosphorylated Vimentin levels significantly decreased in ROCK2 shRNA group, not in ROCK1 shRNA, indicating the dynamic changes in Vimentin phosphorylation at Ser72 may reflect the fact that the level of phosphorylated Vimentin is determined by the activation level of ROCK2. The same result appeared in the over-expression of ROCK2 group (Fig. 5e). Strikingly, there was no prominent ROCK-dependent fluctuations of Ser38-phosphorylated Vimentin with fluctuations of RhoA/ROCK or Rac1/PAK. These data suggested that higher active ROCK and PAK expression with the 

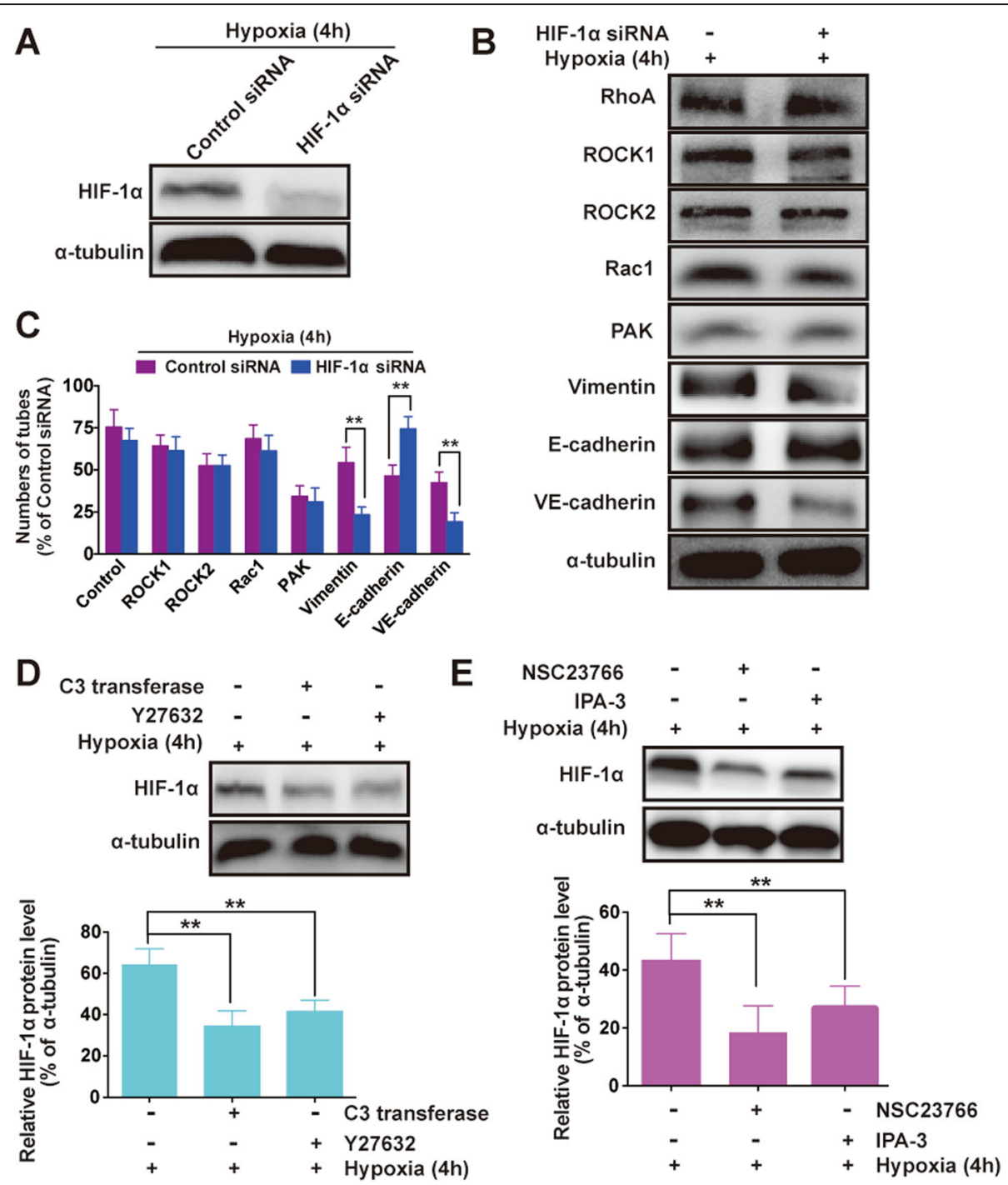

Fig. 3 RhoA/ROCKs and Rac1/PAK act upstream of HIF-1a. a Western blot analysis for the expression of HIF-1a in MHCC97H cell lines transfected with control siRNA or HIF-1a siRNA. b Western blot analysis for RhoA/ROCK, Rac1/PAK, EMT (Vimentin and E-cadherin) and VE-cadherin (a biomarker of VM), in MHCC97H cells transfected with control siRNA or HIF-1a siRNA. The cells were exposed to hypoxia for 4 h. c Quantitated using Image J *P<0.05; ${ }^{*} \mathrm{P}<0.01$ vs. control siRNA. Western blot analysis for HIF-1a expression when treated with (d) C3 transferase or Y27632, and (e) NSC23766 or IPA-3, Quantitated using Image J. The data are expressed as the mean \pm S.E. of three independent experiments. ${ }^{* *} P<0.01$ vs. Hypoxia $(4 \mathrm{~h})$. $\mathrm{h}=$ hours

potential of VM formation, may promote Vimentin phosphorylation at Ser72 and Ser56, which may induce the rearrangement of Vimentin caused by ROCK 2 and PAK.

\section{Discussion}

Tumor hypoxia was a well-known microenvironment occurring for additional growth [27]. HIF-1 is a heterodimer complex which is consisted of two basic helixloop-helix (bHLH) transcription factors (HIF-1 $\alpha$ and HIF-1 $\beta$ ), and it plays a role in responding to hypoxia $[28,29]$. In the hypoxic states, HIF- $1 \alpha$ is stable and it translocates from the cytoplasm to the nucleus to dimerize with HIF-1 $\beta$ then activate downstream target genes which accelerate cancer progression and promote tumor aggressiveness, including VM [5]. The significant role of HIF- $1 \alpha$ in tumor development was first identified due to its abundant overexpression in a broad range of tumor types and its participation in critical aspects of tumor initiation and progression. In our study, HIF- $1 \alpha$ expression was correlated with a higher rate in lymph nodes metastasis and VM presentation, which is an independent prognostic marker for HCC (Table 2; Fig. 1). This observation is in accordance with previous work by $\mathrm{Li}$, et al., who reported particularly HIF- $1 \alpha$-induced vasculogenic mimicry formation in human colorectal cancer cells [30].

RhoA and Rac1, both of the Rho family of small GTPases [31], together with Rho kinase was key 


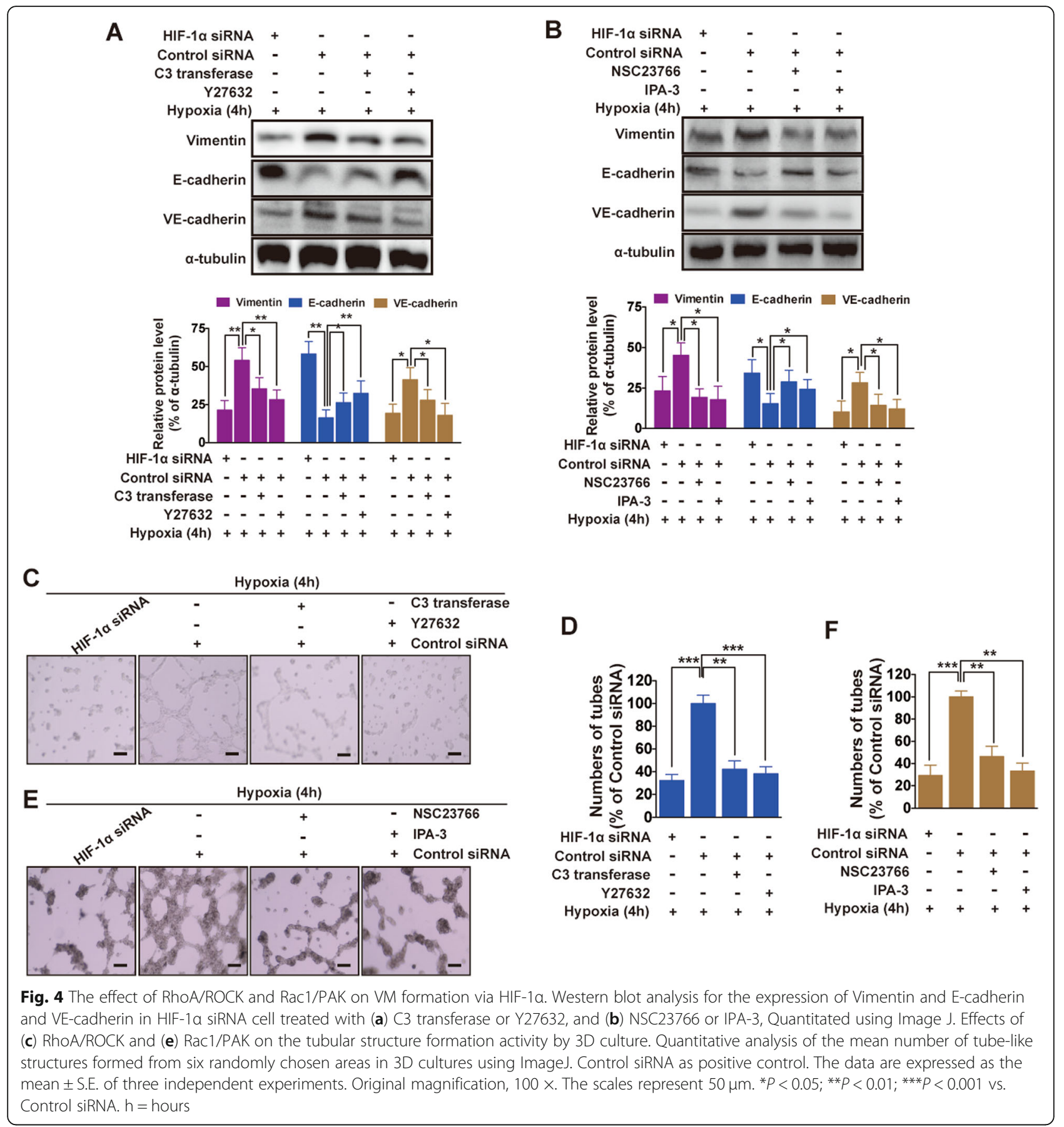

regulator of both cell adhesion and the cytoskeleton. Our previous research mentioned that blocking ROCK would inhibit migration, invasion and VM formation [4]. As a transcription factor, HIF- $1 \alpha$ could affect cell plasticity from several dimensions [32], showed that HIF- $1 \alpha$ may induce VM, similar to our results: HIF- $1 \alpha$ silencing inhibited VM tubes in Matrigel. In light of these results, we were interested in identifying the upstream events that trigger the upregulation of RhoA/ROCK and Rac1/ PAK in VM formation responding to hypoxia. Notably, we mentioned that RhoA may not be essential for the VM process in normoxia condition [4], contrary to our present research. To our knowledge, the relationship between hypoxia and RhoA is very complicated, even contrary [33, 34]. Rho-GTPases, which are regulated by VEGF, play a crucial role in cancer progression $[35,36]$. VEGF-A expression was mediated via both HIF-1 $\alpha$ dependent and -independent mechanisms [37, 38]. Those reports indicated that exposure to hypoxia induces a significant increase in RhoA activity, similar our 


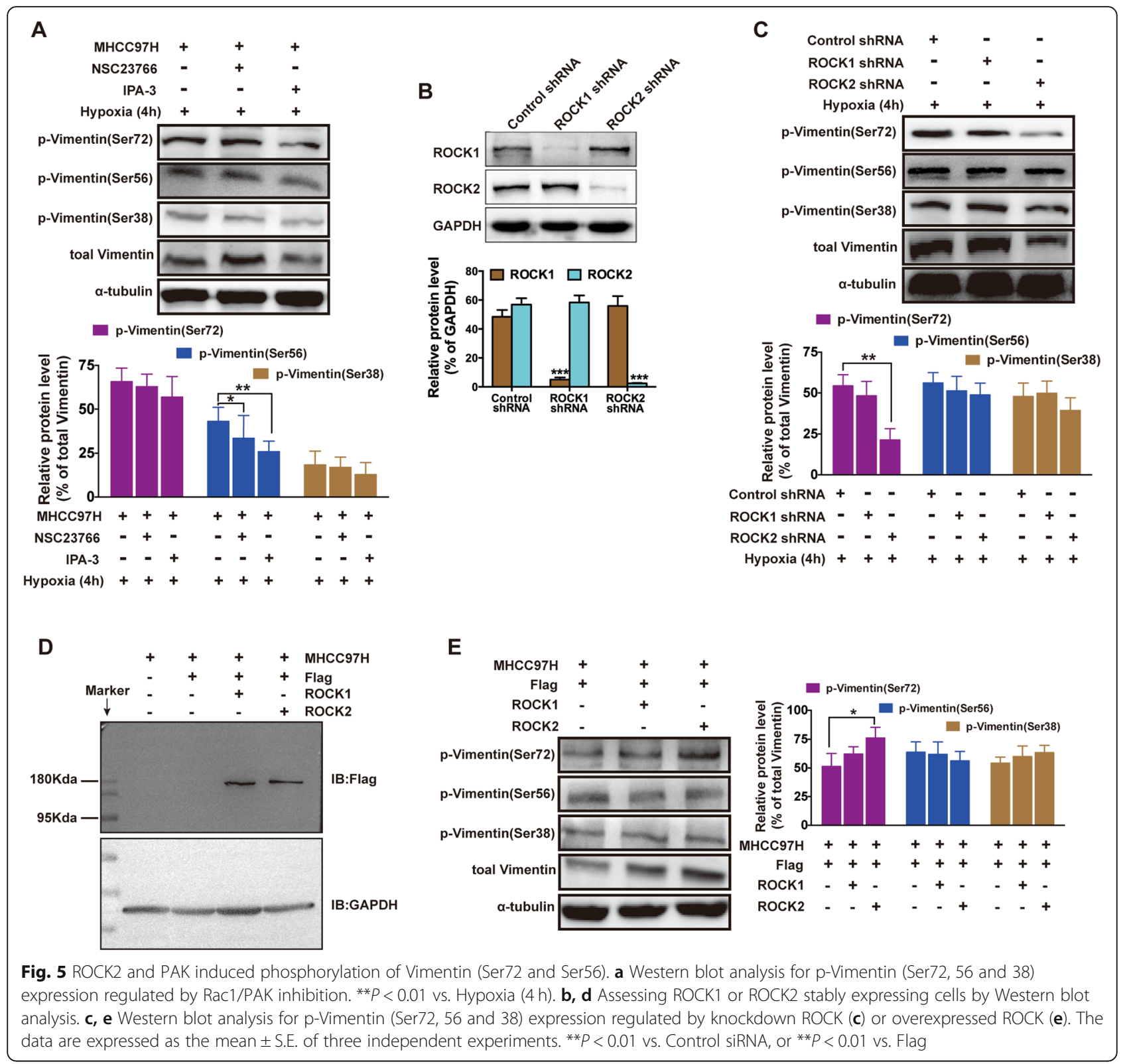

present report. We found that hypoxia upregulated RhoA/ROCK2 and Rac1/PAK protein level, but did not affect the expression of ROCK1. Recent reports have established some cross-talk between the HIF, RhoA/ ROCK and Rac1/PAK pathways. It has been shown that, in some cell types, RhoA is responsible for HIF- $1 \alpha$ mRNA and/or protein induction in low oxygen conditions $[39,40]$. Our results above demonstrated that HIF$1 \alpha$ did not regulate RhoA/ROCK and Rac1/PAK activity, but inhibition of RhoA and Rac1 activity reduces the hypoxic stabilization of HIF-1 $\alpha$, indicating that the small monomeric $G$ protein is involved in HIF- $1 \alpha$ regulation in HCC. In addition, exoenzyme C3, Y27632, NSC23766 or IPA-3 treatment vanished VM formation, confirming the contribution of RhoA/ROCK and Rac1/PAK to VM formation in hypoxia. In summary, our results show that hypoxia induces an increase in RhoA and Rac1 activity and stabilizes HIF- $1 \alpha$ protein, suggesting the existence of cross-talk between RhoA, Rac1 and HIF pathways.

The FAK-Rac-PAK pathway also responds to mechanical signals and is important in Vimentin network disassembly. FAK phosphorylation facilitates Rac activation [41], then activates PAK and alters cytoskeletal dynamics [42]. PAK phosphorylates Vimentin [43] to cause network disassembly. We show that PAK inhibition decrease p-Vimentin (Ser 56) protein level, but did not affect the expression of p-Vimentin (Ser 72 or 38) 


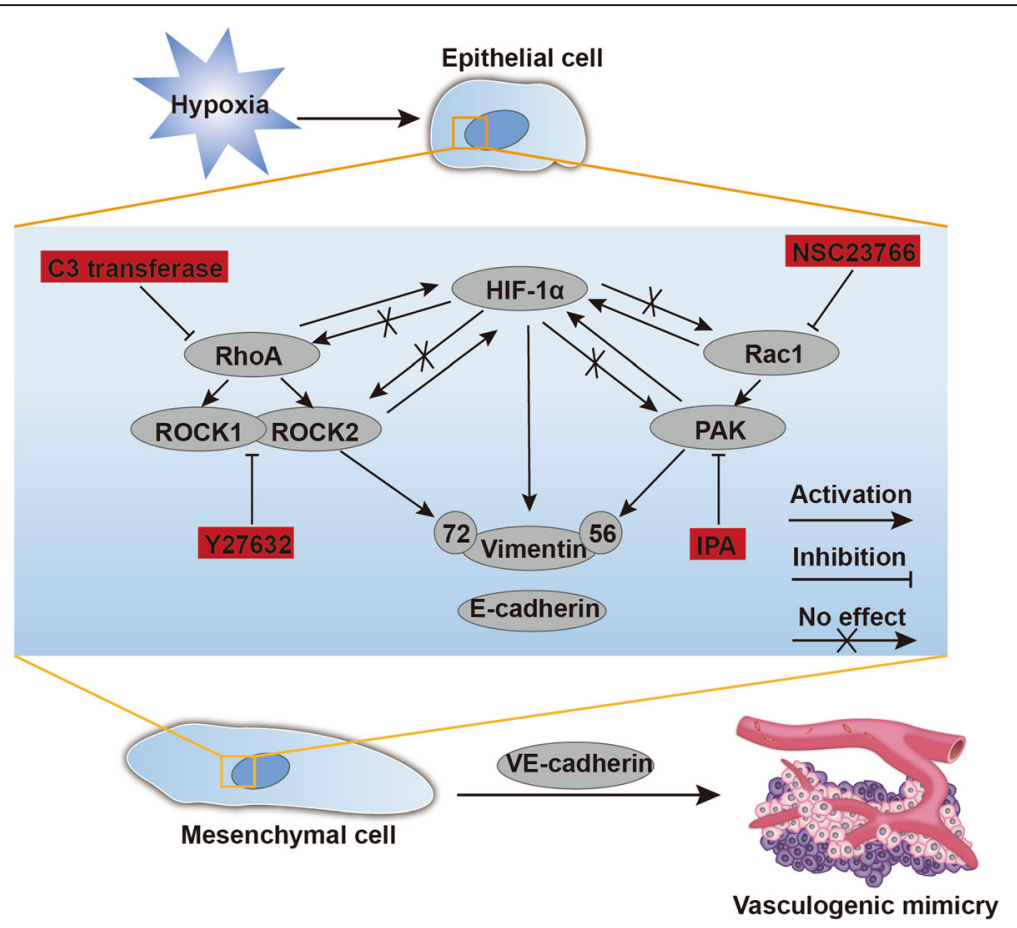

Fig. 6 Schematic overview summarizing the functional significance and regulation of RhoA/ROCK, Rac1/PAK and HIF-1a exposed to hypoxia in HCC. Hypoxia triggers the upregulation of RhoA/ROCK2 and Rac1/PAK, subsequently modulates HIF-1a stabilization, leading to elevated Vimentin expression with phosphorylation at Ser72 and Ser56, which finally induces VM development via promoting the secretion of VE-cadherin accompany occurrences of EMT (Epithelial cell transform to Mesenchymal cell) in hypoxia

(Fig. 5a), similar to other report [44]. The results of Rac1 affecting p-Vimentin (Ser 56) protein could be caused by the loss of PAK activation and consequent unstabilization of the Vimentin. ROCKs consist of two isoforms: ROCK1 and ROCK2. ROCK1(-/-) mice display failure of the eyelid and ventral body wall closure and die soon after birth [45], while ROCK2(-/ -) mice experience embryonic lethality due to intrauterine growth retardation and placental dysfunction [46], suggesting that the regulation and signaling of these two proteins may be divergent to a measurable degree. Hypoxia sensitized the RhoA/ROCK2 signaling pathway in $\mathrm{HCC}$ (Fig. 2b and e), then enhancement of p-Vimentin (Ser 72) was observed in Flag-ROCK2 but not in Flag-ROCK1 cell lines (Fig. 5c and e). However, ROCK1 was upregulated in neonatal rat ventricular myocyte subjected to hypoxia [47]. These results indicated that the roles of ROCK1 were different from those of ROCK2 in hypoxic condition and various pathology [48].

EMT was closely related to an aggressive tumor phenotype in HCC [49]. Here, stable knockdown of HIF$1 \alpha$ in MHCC97H cell lines increased E-cadherin and downregulated Vimentin protein expression (Fig. 3b). So the HIF-1 $\alpha$ could induce EMT, which brought out cell plasticity. HIF- $1 \alpha$ was a critical parameter in VM [50], VE-cadherin was the first reported biomarker of VM [3]. In this study, inhibition of VE-cadherin followed HIF-1 $\alpha$ siRNA transfection (Fig. 3b), concurring with 3D culture assay (Fig. 4c and d). Our data suggested that VM was observed after EMT in vitro.

Taken together, we showed that HIF-1 $\alpha$ and Vimentin contributed to a poor prognosis in HCC patients. Then, we expounded that hypoxia could enhance RhoA/ROCK and Rac1/PAK expression, further regulate HIF- $1 \alpha$ expression. Ultimately, RhoA/ROCK and Rac1/PAK induced VM formation by HIF-1 $\alpha$ stabilization and EMT with p-Vimentin (Ser72 and 56) activated (Fig. 6).

\section{Conclusions}

This study showed that HIF- $1 \alpha$ and Vimentin contributed to a poor prognosis in HCC patients. Hypoxia could enhance RhoA/ROCK and Rac1/PAK expression, further regulate HIF- $1 \alpha$ expression. Ultimately, RhoA/ ROCK and Rac1/PAK induced VM formation by HIF- $1 \alpha$ stabilization and EMT with p-Vimentin (Ser72 and 56) activated. 


\section{Supplementary information}

Supplementary information accompanies this paper at https://doi.org/10. 1186/s12885-019-6501-8

Additional file 1: Table S1. The information of antibodies used in this study

Additional file 2: Table S2. shRNA Construct Sequences

Additional file 3: Table S3. Sequences of primers

\section{Abbreviations}

EMT: Epithelial-mesenchymal transition; HCC: Hepatocellular carcinoma; HIF1a: Hypoxia inducible factor-1a; IHC: Immunohistochemical; PAK: p21activated kinase; PAS: Periodic acid-Schiff; ROCK: Rho kinases; shRNA: Short hairpin RNA; siRNA: Small interfering RNA; VM: Vasculogenic mimicry

\section{Acknowledgements}

This work was supported by grants from the National Natural Science Foundation of China (NSFC, No.81572449 and No.81602524); sponsored by the Interdisciplinary Program of Shanghai Jiao Tong University (No.YG2015QN18)

\section{Authors' contributions}

LQ and LGL designed the study. ZJG and ZHM performed the experiments and analyzed the data. ZHM drafted the manuscript. ZJG revised the manuscript. All authors reviewed and approved the final manuscript.

\section{Funding}

This work was supported by grants from the National Natural Science Foundation of China (NSFC, No.81572449 and No.81602524) in the design of the study and collection, analysis and interpretation of data; sponsored by the Interdisciplinary Program of Shanghai Jiao Tong University (No.YG2015QN18) in writing the manuscript.

\section{Availability of data and materials}

The datasets used and analyzed during the present study are available from the corresponding author upon reasonable request.

\section{Ethics approval and consent to participate}

Written informed consent was obtained from all participants, and the study was approved and supervised by the Ethics Committee of the Shanghai General Hospital.

\section{Consent for publication}

Not applicable.

\section{Competing interests}

The authors declare that they have no competing interests.

Received: 7 March 2019 Accepted: 26 December 2019

Published online: 13 January 2020

\section{References}

1. Siegel RL, Miller KD, Jemal A. Cancer statistics, 2017. CA Cancer J Clin. 2017; 67(1):7-30.

2. Ryder SD. Guidelines for the diagnosis and treatment of hepatocellular carcinoma (HCC) in adults. Gut. 2003:52(Supplement 3):1-8.

3. Maniotis AJ, Folberg R, Hess A, Seftor EA, Gardner LMG, Pe'er J, Trent JM, Meltzer PS, Hendrix MJC. Vascular channel formation by human melanoma cells in vivo and in vitro: Vasculogenic mimicry. Am J Pathol. 1999;155(3): 739-52.

4. Z Zhang JG, Li XY, Wang YZ, Zhang QD, Gu SY, Wu X, Zhu GH, Li Q, Liu GL. ROCK is involved in Vasculogenic mimicry formation in hepatocellular carcinoma cell line. PLoS One. 2014;9(9):8.

5. Xu Y, Li Q, Li XY, Yang QY, Xu WW, Liu GL. Short-term anti-vascular endothelial growth factor treatment elicits vasculogenic mimicry formation of tumors to accelerate metastasis. J Exp Clin Cancer Res. 2012;31:7.

6. Cairns RA, Harris IS, Mak TW. Regulation of cancer cell metabolism. Nat Rev Cancer. 2011;11(2):85-95
7. Maxwell PH, Wiesener MS, Chang GW, Clifford SC, Vaux EC, Cockman ME, Wykoff CC, Pugh CW, Maher ER, Ratcliffe PJ. The tumour suppressor protein VHL targets hypoxia-inducible factors for oxygen-dependent proteolysis. Nature. 1999:399(6733):271-5.

8. Wang M, Zhao X, Zhu D, Liu T, Liang X, Liu F, Zhang Y, Dong X, Sun B. HIF1alpha promoted vasculogenic mimicry formation in hepatocellular carcinoma through LOXL2 up-regulation in hypoxic tumor microenvironment. J Exp Clin Cancer Res. 2017;36(1):60.

9. Yang J, Zhu DM, Zhou XG, Yin N, Zhang Y, Zhang ZX, Li DC, Zhou J. HIF-2 alpha promotes the formation of vasculogenic mimicry in pancreatic cancer by regulating the binding of Twist1 to the VE-cadherin promoter. Oncotarget. 2017:8(29):47801-15.

10. Rane CK, Minden A. P21 activated kinases: structure, regulation, and functions. Small GTPases. 2014;5:e28003.

11. Riento K, Ridley AJ. Rocks: multifunctional kinases in cell behaviour. Nat Rev Mol Cell Biol. 2003;4(6):446-56.

12. Gadea G, de Toledo M, Anguille C, Roux P. Loss of p53 promotes RhoAROCK-dependent cell migration and invasion in 3D matrices. J Cell Biol. 2007:178(1):23-30

13. Sahai E, Marshall CJ. Differing modes of tumour cell invasion have distinct requirements for rho/ROCK signalling and extracellular proteolysis. Nat Cell Biol. 2003;5(8):711-9.

14. Xiong NY, Li S, Tang K, Bai HX, Peng YT, Yang H, Wu CH, Liu YY. Involvement of caveolin-1 in low shear stress-induced breast cancer cell motility and adhesion: roles of FAK/Src and ROCK/p-MLC pathways. Biochim Biophys Acta-Mol Cell Res. 2017;1864(1):12-22.

15. Bryan BA, Dennstedt E, Mitchell DC, Walshe TE, Noma K, Loureiro R, SaintGeniez M, Campaigniac J-P, Liao JK, D'Amore PA. RhoA/ROCK signaling is essential for multiple aspects of VEGF-mediated angiogenesis. FASEB J. 2010;24(9):3186-95.

16. Leong SY, Faux CH, Turbic A, Dixon KJ, Turnley AM. The rho kinase pathway regulates mouse adult neural precursor cell migration. Stem Cells. 2011; 29(2):332-43.

17. Sun $T$, Zhao $N$, Zhao $X L$, Gu Q, Zhang SW, Che N, Wang XH, Du J, Liu $Y X$, Sun BC. Expression and functional significance of Twist1 in hepatocellular carcinoma: its role in vasculogenic mimicry. Hepatology. 2010;51(2):545-56.

18. Wang L, Lin L, Chen X, Sun L, Liao YL, Huang N, Liao WJ. Metastasisassociated in colon cancer-1 promotes vasculogenic mimicry in gastric cancer by upregulating TWIST1/2. Oncotarget. 2015;6(13):11492-506.

19. Chaw SY, Abdul Majeed A, Dalley AJ, Chan A, Stein S, Farah CS. Epithelial to mesenchymal transition (EMT) biomarkers--E-cadherin, beta-catenin, APC and Vimentin--in oral squamous cell carcinogenesis and transformation. Oral Oncol. 2012;48(10):997-1006

20. Lei S, Tian YP, Xiao WD, Li S, Rao XC, Zhang JL, Yang J, Hu XM, Chen W. ROCK is involved in vimentin phosphorylation and rearrangement induced by dengue virus. Cell Biochem Biophys. 2013;67(3):1333-42.

21. Matveeva EA, Venkova LS, Chernoivanenko IS, Minin AA. Vimentin is involved in regulation of mitochondrial motility and membrane potential by Rac1. Biol Open. 2015;4(10):1290-7.

22. Albelda SM, Muller WA, Buck CA, Newman PJ. Molecular and cellular properties of PECAM-1 (endoCAM/CD31): a novel vascular cell-cell adhesion molecule. J Cell Biol. 1991;114(5):1059-68.

23. Bruick RK, McKnight SL. A conserved family of prolyl-4-hydroxylases that modify HIF. Science (New York, NY). 2001:294(5545):1337-40.

24. Lando D, Peet DJ, Whelan DA, Gorman JJ, Whitelaw ML. Asparagine hydroxylation of the HIF transactivation domain a hypoxic switch. Science (New York, NY). 2002;295(5556):858-61.

25. Takata K, Morishige K, Takahashi T, Hashimoto K, Tsutsumi S, Yin L, Ohta T, Kawagoe J, Takahashi K, Kurachi H. Fasudil-induced hypoxia-inducible factor-1alpha degradation disrupts a hypoxia-driven vascular endothelial growth factor autocrine mechanism in endothelial cells. Mol Cancer Ther. 2008;7(6):1551-61

26. Sin WC, Chen XQ, Leung T, Lim L. RhoA-binding kinase alpha translocation is facilitated by the collapse of the vimentin intermediate filament network. Mol Cell Biol. 1998;18(11):6325-39.

27. Li S, Meng W, Guan Z, Guo Y, Han X. The hypoxia-related signaling pathways of vasculogenic mimicry in tumor treatment. Biomed Pharmacother. 2016;80:127-35

28. Burrows N, Babur M, Resch J, Williams KJ, Brabant G. Hypoxia-inducible factor in thyroid carcinoma. J Thyroid Res. 2011;2011:762905. 
29. Semenza GL. HIF-1: upstream and downstream of cancer metabolism. Curr Opin Genet Dev. 2010;20(1):51-6.

30. Li W, Zong S, Shi Q, Li H, Xu J, Hou F. Hypoxia-induced vasculogenic mimicry formation in human colorectal cancer cells: involvement of HIF-1a, Claudin-4, and E-cadherin and Vimentin. Sci Rep. 2016;6:37534.

31. Ridley AJ. Rho GTPases and cell migration. J Cell Sci. 2001;114(Pt 15):2713-22.

32. Masoud GN, Li W. HIF-1 alpha pathway: role, regulation and intervention for cancer therapy. Acta Pharm Sin B. 2015;5(5):378-89.

33. Raheja LF, Genetos DC, Wong A, Yellowley CE. Hypoxic regulation of mesenchymal stem cell migration: the role of RhoA and HIF-1alpha. Cell Biol Int. 2011;35(10):981-9.

34. Pacary E, Tixier E, Coulet F, Roussel S, Petit E, Bernaudin M. Crosstalk between HIF-1 and ROCK pathways in neuronal differentiation of mesenchymal stem cells, neurospheres and in PC12 neurite outgrowth. Mol Cell Neurosci. 2007:35(3):409-23.

35. Boreddy SR, Sahu RP, Srivastava SK. Benzyl isothiocyanate suppresses pancreatic tumor angiogenesis and invasion by inhibiting HIF-alpha/NEGF/ rho-GTPases: pivotal role of STAT-3. PLoS One. 2011;6(10):e25799.

36. Chen MC, Lee CF, Huang WH, Chou TC. Magnolol suppresses hypoxiainduced angiogenesis via inhibition of HIF-1alpha/NEGF signaling pathway in human bladder cancer cells. Biochem Pharmacol. 2013;85(9):1278-87.

37. Dodd KM, Yang J, Shen MH, Sampson JR, Tee AR. mTORC1 drives HIF1alpha and VEGF-A signalling via multiple mechanisms involving 4E-BP1, S6K1 and STAT3. Oncogene. 2015;34(17):2239-50.

38. Xu M, Zheng YL, Xie XY, Liang JY, Pan FS, Zheng SG, Lu MD. Sorafenib blocks the HIF-1alpha/NEGFA pathway, inhibits tumor invasion, and induces apoptosis in hepatoma cells. DNA Cell Biol. 2014;33(5):275-81.

39. Turcotte S, Desrosiers RR, Beliveau R. HIF-1alpha mRNA and protein upregulation involves rho GTPase expression during hypoxia in renal cell carcinoma. J Cell Sci. 2003;116(Pt 11):2247-60.

40. Hayashi M, Sakata M, Takeda T, Tahara M, Yamamoto T, Minekawa R, Isobe A, Tasaka K, Murata Y. Hypoxia up-regulates hypoxia-inducible factor-1alpha expression through RhoA activation in trophoblast cells. J Clin Endocrinol Metab. 2005;90(3):1712-9.

41. Chang F, Lemmon CA, Park D, Romer LH. FAK potentiates Rac1 activation and localization to matrix adhesion sites: a role for betaPIX. Mol Biol Cell. 2007;18(1):253-64.

42. Edwards DC, Sanders LC, Bokoch GM, Gill GN. Activation of LIM-kinase by Pak1 couples Rac/Cdc42 GTPase signalling to actin cytoskeletal dynamics. Nat Cell Biol. 1999;1(5):253-9.

43. Goto H, Tanabe K, Manser E, Lim L, Yasui Y, Inagaki M. Phosphorylation and reorganization of vimentin by p21-activated kinase (PAK). Genes Cells. 2002;7(2):91-7.

44. Li QF, Spinelli AM, Wang R, Anfinogenova Y, Singer HA, Tang DD. Critical role of vimentin phosphorylation at Ser-56 by p21-activated kinase in vimentin cytoskeleton signaling. J Biol Chem. 2006;281(45):34716-24.

45. Shimizu Y, Thumkeo D, Keel J, Ishizaki T, Oshima H, Oshima M, Noda Y, Matsumura F, Taketo MM, Narumiya S. ROCK-I regulates closure of the eyelids and ventral body wall by inducing assembly of actomyosin bundles. J Cell Biol. 2005;168(6):941-53.

46. Thumkeo D, Keel J, Ishizaki T, Hirose M, Nonomura K, Oshima H, Oshima M, Taketo MM, Narumiya S. Targeted disruption of the mouse rho-associated kinase 2 gene results in intrauterine growth retardation and fetal death. Mol Cell Biol. 2003;23(14):5043-55.

47. Gonzalez-Rodriguez P, Falcon D, Castro MJ, Urena J, Lopez-Barneo J, Castellano A. Hypoxic induction of T-type Ca2+ channels in rat cardiac myocytes: role of HIF-1 and RhoA/ROCK signalling. J Physiol-London. 2015;593(21):4729-45.

48. Loirand G. Rho kinases in health and disease: from basic science to translational research. Pharmacol Rev. 2015;67(4):1074-95.

49. Giannelli G, Koudelkova P, Dituri F, Mikulits W. Role of epithelial to mesenchymal transition in hepatocellular carcinoma. J Hepatol. 2016;65(4); 798-808.

50. Du J, Sun B, Zhao X, Gu Q, Dong X, Mo J, Sun T, Wang J, Sun R, Liu Y. Hypoxia promotes vasculogenic mimicry formation by inducing epithelialmesenchymal transition in ovarian carcinoma. Gynecol Oncol. 2014;133(3): 575-83

\section{Publisher's Note}

Springer Nature remains neutral with regard to jurisdictional claims in published maps and institutional affiliations.

\section{Ready to submit your research? Choose BMC and benefit from:}

- fast, convenient online submission

- thorough peer review by experienced researchers in your field

- rapid publication on acceptance

- support for research data, including large and complex data types

- gold Open Access which fosters wider collaboration and increased citations

- maximum visibility for your research: over $100 \mathrm{M}$ website views per year

At BMC, research is always in progress.

Learn more biomedcentral.com/submissions 